\title{
High-grade serous ovarian cancer cell lines exhibit heterogeneous responses to growth factor stimulation
}

\author{
Danielle L. Bourgeois, Karl A. Kabarowski, Veronica L. Porubsky and Pamela K. Kreeger
}

\begin{abstract}
Background: The factors driving the onset and progression of ovarian cancer are not well understood. Recent reports have identified cell lines that are representative of the genomic pattern of high-grade serous ovarian cancer (HGSOC), in which greater than $90 \%$ of tumors have a mutation in TP53. However, many of these representative cell lines have not been widely used so it is unclear if these cell lines capture the variability that is characteristic of the disease.
\end{abstract}

Methods: We investigated six TP53-mutant HGSOC cell lines (Caov3, Caov4, OV90, OVCA432, OVCAR3, and OVCAR4) for migration, MMP2 expression, proliferation, and VEGF secretion, behaviors that play critical roles in tumor progression. In addition to comparing baseline variation between the cell lines, we determined how these behaviors changed in response to four growth factors implicated in ovarian cancer progression: HB-EGF, NRG1 $\beta$, IGF1, and HGF.

Results: Baseline levels of each behavior varied across the cell lines and this variation was comparable to that seen in tumors. All four growth factors impacted cell proliferation or VEGF secretion, and HB-EGF, NRG1 $\beta$, and HGF impacted wound closure or MMP2 expression in at least two cell lines. Growth factor-induced responses demonstrated substantial heterogeneity, with cell lines sensitive to all four growth factors, a subset of the growth factors, or none of the growth factors, depending on the response of interest. Principal component analysis demonstrated that the data clustered together based on cell line rather than growth factor identity, suggesting that response is dependent on intrinsic qualities of the tumor cell rather than the growth factor.

Conclusions: Significant variation was seen among the cell lines, consistent with the heterogeneity of HGSOC.

Keywords: Ovarian cancer, Growth factors, HB-EGF, NRG1 $\beta$, IGF1, HGF, HGSOC, Metastasis, Tumor heterogeneity

\section{Background}

Ovarian cancer is the deadliest gynecological cancer in the developed world, with nearly two-thirds of patients diagnosed with advanced, metastatic disease [1]. Most of these patients initially respond to standard treatment of surgical debulking and chemotherapy, but over $70 \%$ exhibit disease recurrence and eventual chemoresistance. High-grade serous ovarian cancer (HGSOC), a subtype characterized by a mutation in TP53, a low rate of other mutations, and extensive DNA copy number changes, is

\footnotetext{
*Correspondence: kreeger@wisc.edu

Department of Biomedical Engineering, University of Wisconsin-Madison, 1111 Highland Avenue, Madison, WI 53705, USA
}

the most aggressive and most common subtype of ovarian cancer, accounting for two-thirds of deaths $[2,3]$. Due to the limited animal models that mimic the disease $[4,5]$, HGSOC has been primarily studied in vitro and through xenograft models with cell lines. However, a recent analysis of ovarian cancer cell lines in the Cancer Cell Line Encyclopedia (CCLE) indicated that the most commonly used cellular models of HGSOC (i.e., SKOV3 and A2780) do not mimic the genomic characteristics of tumors in The Cancer Genome Atlas (TCGA) database and suggested that future research should use more representative lines to develop improved treatment strategies [6]. Extensive patient-to-patient variation is observed within the HGSOC subtype; therefore, it will be 
important to determine if limiting studies to these representative lines can recapitulate this heterogeneity. To address this question, we performed the first comprehensive study of representative HGSOC cell lines to examine the variation in their baseline and growth factor-induced behaviors with respect to processes that are important in metastasis.

Unlike other solid tumors, ovarian cancer is not restricted to metastasis through the blood and lymph systems; instead, tumor cells can exfoliate from the ovary and attach to organs in the peritoneum, especially the omentum [7]. This peritoneal metastasis is a complex process that relies on many different cellular actions, including migration, extracellular matrix remodeling, proliferation, and angiogenesis. Tumor cell migration is a key step for dissemination of the tumor along the peritoneum [8], and has been modeled in vitro using two-dimensional cell migration assays. In addition to this mechanism of spreading, ovarian cancer cells can detach, transport through the peritoneal fluid and attach to new metastatic sites. The attachment of these cells into their new sites is mediated in part by matrix-metalloproteinase-2 (MMP2) [9]; MMP2 is also responsible for invasion of the tumor deeper into the tissue [10]. Studies have found that MMP2 levels in ascites fluid increase in advanced stage ovarian cancer [11] and overexpression of MMP2 in peritoneal implants correlates with elevated mortality risk [12]. Following implantation and invasion, continued growth and viability of the tumors is maintained through cell proliferation and angiogenesis. Not surprisingly, advanced stages of ovarian cancer and mortality risk are both associated with high rates of proliferation [13]. As in other solid tumors, angiogenesis in ovarian cancer is mediated by the production of angiogenic factors such as vascular endothelial growth factor (VEGF) that recruit new vessels from the native vasculature [14-16].

The different stages of HGSOC metastasis are influenced by the presence of growth factors and cytokines in the tumor microenvironment, which in HGSOC includes ascites fluid. For example, heparin-binding EGF-like growth factor (HB-EGF), neuregulin-1 beta (NRG1 $\beta$ ), insulin-like growth factor 1 (IGF1), and hepatocyte growth factor (HGF) are all expressed in tumors and found at higher levels in ascites fluid of ovarian cancer patients compared to healthy controls [17-21]. Elevated HB-EGF expression has been associated with shorter progressionfree survival [22]; HB-EGF treatment induced invasion and VEGF production by SKOV3 in vitro and promoted peritoneal dissemination of xenografts [23]. Autocrine NRG1 $\beta$ increased cell growth and decreased survival time in several xenograft mouse models of ovarian cancer [21]. Overexpression of IGF1 was associated with shorter progression-free survival [24] and has been shown to increase proliferation of OVCAR3 in vitro [25]. Elevated serum levels of HGF were exhibited in $>90 \%$ of tumors and correlated to shorter overall survival of ovarian cancer patients [26]. In vitro, HGF mediated an epithelial-to-mesenchymal transition and sustained anchorage-independent growth of ovarian cancer cells [27, 28].

Therefore, to determine if HGSOC cell lines that have genomic profiles similar to TCGA tumors (Caov3, Caov4, OV90, OVCA432, OVCAR3, OVCAR4) demonstrate heterogeneity in the various metastatic processes, we examined migration, $M M P 2$ expression, proliferation, and VEGF secretion in response to HB-EGF, NRG1 $\beta$, IGF1, and HGF.

\section{Results}

Tumor cell migration in response to growth factors varied across HGSOC cell lines

Progression in HGSOC is marked by the dissemination of tumor cells throughout the peritoneum [8], with tumor cells present as both single cells and as aggregates [29]. Therefore, to model the behavior of these different cellular presentations, collective cell migration was examined by wound assays and single cell motility was modeled utilizing transwell assays. In the wound assays, we determined that all six cell lines migrated in the absence of stimulatory factors and that the extent of wound closure varied across the cell lines, ranging from $7.6 \%$ for OVCAR3 to $41.4 \%$ for OVCAR4 (Fig. 1). Following growth factor treatment, we observed that HGSOC cell lines had significantly increased migration after treatment with (1) three of the growth factors (Caov4, OVCAR3), (2) one of the growth factors (Caov3, OVCA432, OVCAR4), or (3) none of the tested growth factors (OV90). Overall, Caov4 and OVCAR3 had the most similar response, with increased migration when treated with HB-EGF, NRG1 $\beta$, or HGF; however, Caov4 had consistently greater wound closure. With respect to the individual growth factors, HGF had the broadest effect, with increased migration in Caov4, OVCA432, OVCAR3, and OVCAR4. Caov3, Caov4, and OVCAR3 all had increased wound closure when treated with HBEGF, while only Caov4 and OVCAR3 were sensitive to NRG1 $\beta$ treatment. None of the cell lines studied exhibited increased wound closure after IGF1 treatment.

Not surprisingly given the different biological mechanisms involved [30], differences in migration were observed between the wound and transwell assays. In contrast to the variability seen with wound closure, most of the cell lines exhibited minimal levels of baseline migration through transwells (Fig. 2). In addition, Caov4, OV90, OVCAR3, and OVCAR4 were unresponsive to all of the tested growth factors. Caov3 and OVCA432 had increased migration in response to HB-EGF, and 


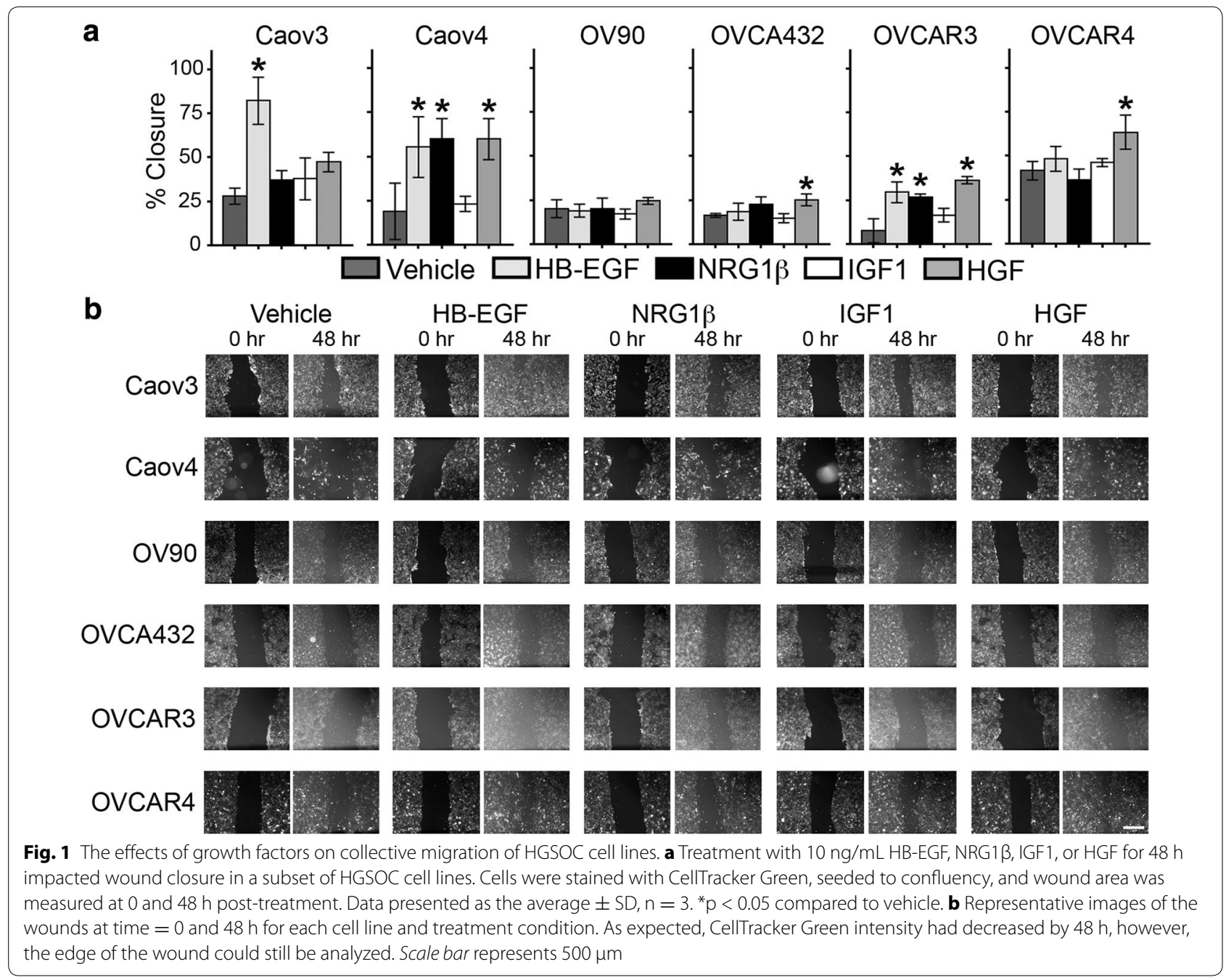

OVCA432 was also sensitive to NRG1 $\beta$. Consistent with the wound assay, IGF1 did not impact migration for any of the cell lines in the transwell assay. Interestingly, none of the cell lines had increased migration in response to HGF in transwell assays, despite HGF impacting wound closure in four of the cell lines (Fig. 1).

\section{MMP levels varied across HGSOC cell lines}

MMPs are a critical component of metastasis in solid tumors, enabling the degradation and remodeling of extracellular matrix as tumor cells invade through the basement membrane and stroma [31]. To examine variation in the remodeling characteristics of these HGSOC cells, conditioned media was first assayed to characterize the total level of MMPs secreted by the cell panel in the absence of growth factor stimulation (Fig. 3a). OV90 had the lowest levels of MMPs and OVCAR3 the highest levels. MMP2 has been shown to play a major role in mediating ovarian cancer cell attachment to the omentum and enabling tumor cells to invade through the extracellular matrix to establish further metastases $[9,10]$. Therefore, we next examined the expression of $M M P 2$ and found that all of the cell lines had detectable levels (Fig. 3). Following growth factor treatment, cells had altered $M M P 2$ levels in response to (1) two growth factors (Caov4, OVCA432, OVCAR4), (2) one growth factor (Caov3, OVCAR3), or (3) none of the tested growth factors (OV90). In general, OVCAR3 and OVCAR4 showed the most similar patterns of sensitivity to the different growth factors. Most of these effects were modest, with only OVCA432 demonstrating increases in $M M P 2$ of greater than twofold after growth factor stimulation. With respect to the individual growth factors, our results demonstrated that HB-EGF increased MMP2 levels in OVCA432, OVCAR3 and OVCAR4, and NRG1 $\beta$ increased MMP2 expression in Caov4 and OVCA432. Similar to the results for migration (Figs. 1, 2), IGF1 did not significantly impact $M M P 2$ expression in any of the 


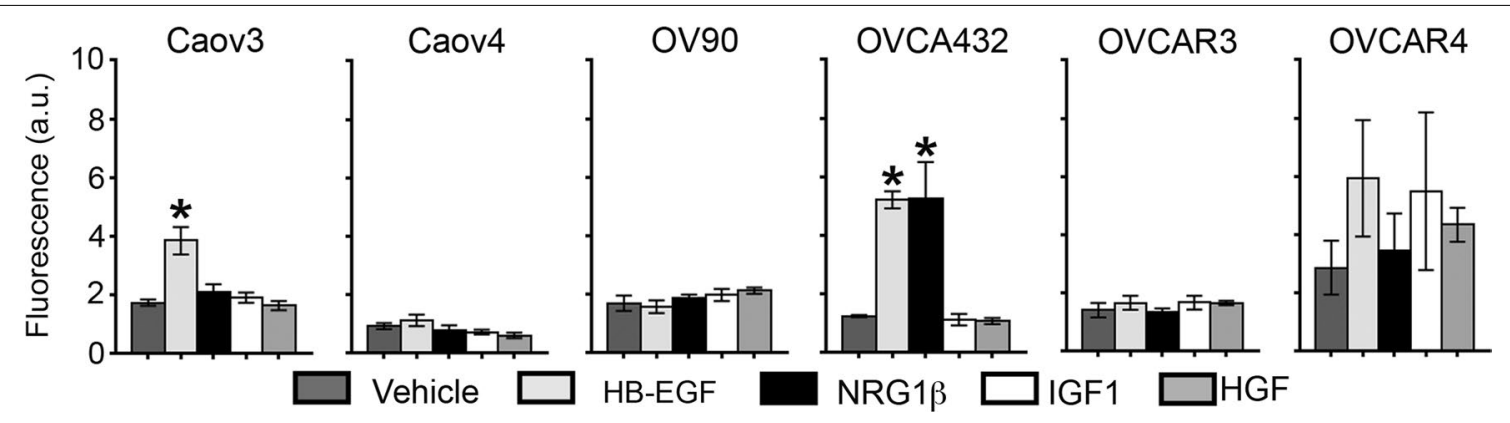

Fig. 2 The effects of growth factors on single cell migration of HGSOC cell lines. HGSOC cell lines were seeded in transwells with $10 \mathrm{ng} / \mathrm{mL} \mathrm{HB}-\mathrm{EGF}$, NRG1 $\beta$, IGF1, or HGF in the bottom compartment. Following $48 \mathrm{~h}$, cells that had migrated through the transwell were stained with Calcein-AM and the relative fluorescence was measured. For every cell line, an MDA-MB-231 positive control was performed in parallel; fluorescence for these cells was at least fivefold higher than for the HGSOC conditions. Data presented as the average $\pm S D, n=3$. ${ }^{*} p<0.05$ compared to vehicle

a

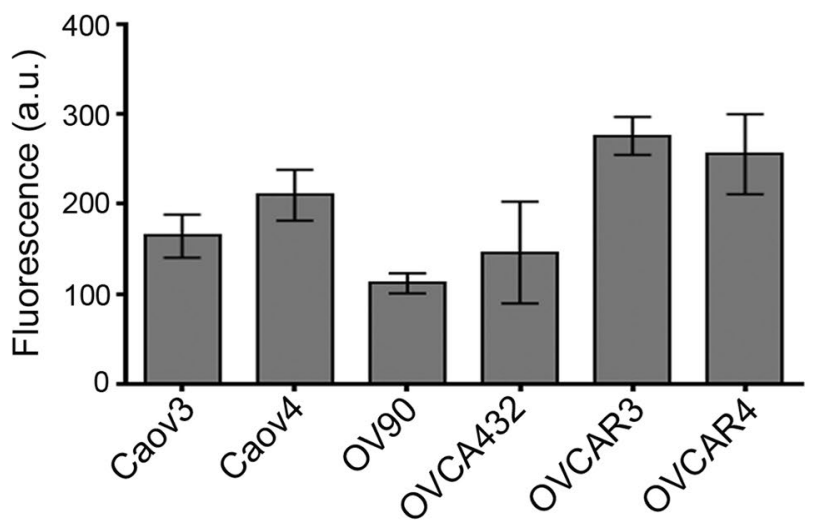

b

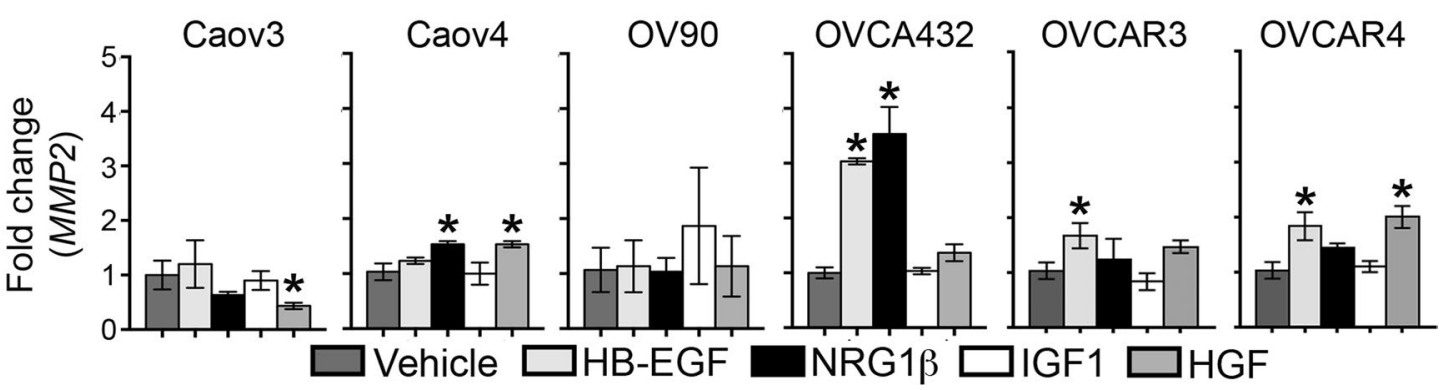

Fig. 3 Growth factor-induced changes in MMP2 expression of HGSOC cell lines. a Total baseline levels of active MMPs in conditioned media was determined to vary across the cell lines when assayed with a fluorogenic MMP substrate. b Treatment with $10 \mathrm{ng} / \mathrm{mL}$ HB-EGF, NRG1 $\beta$, IGF1, or HGF for $24 \mathrm{~h}$ impacted MMP2 expression in a subset of HGSOC cell lines. Expression levels were measured by qRT-PCR and fold change was determined using concurrently assayed GAPDH levels. Data presented as the average $\pm S D, n=3$. ${ }^{*} p<0.05$ compared to vehicle

HGSOC cells tested. HGF increased MMP2 in Caov4 and OVCAR4 but decreased levels in Caov3.

\section{Tumor cell proliferation in response to growth factors varied across HGSOC cell lines}

Elevated cell proliferation is associated with the advanced stages of HGSOC [13]. Therefore, we determined the percentage of cells in S-phase after treatment with vehicle, HB-EGF, NRG1 $\beta$, IGF1, or HGF (Fig. 4). Despite the extended length of time in serum-free media, all cell lines continued to proliferate robustly and appeared healthy. A range of baseline levels of proliferation was detected (16.8 \% for Caov4 to $34.8 \%$ for OVCAR4). We observed that HGSOC cell lines had significantly 


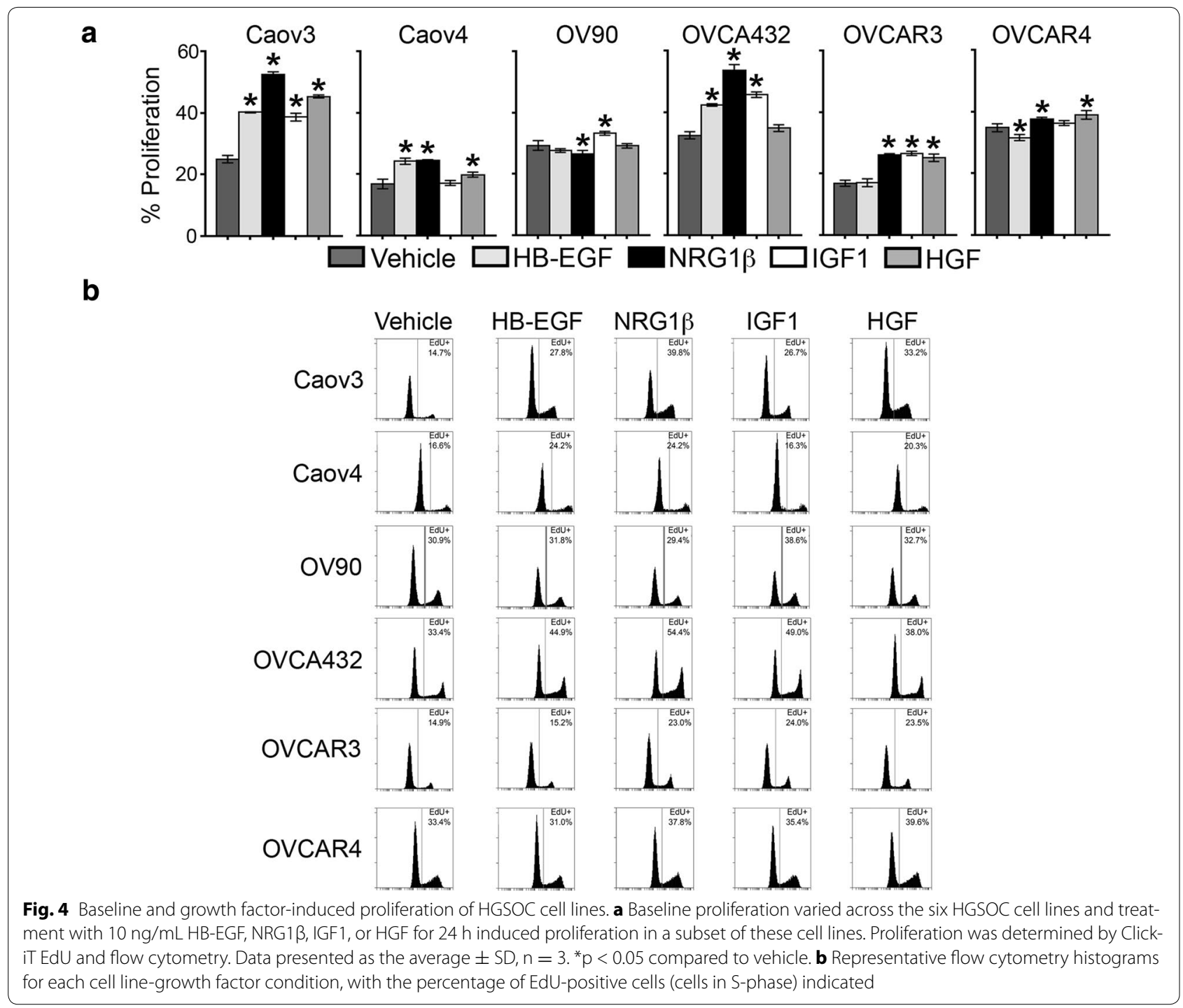

increased proliferation following treatment with (1) all of the growth factors (Caov3) or (2) a subset of the growth factors (Caov4, OV90, OVCA432, OVCAR3, OVCAR4). In contrast to migration and $M M P 2$ expression, there were no cell lines insensitive to all four growth factors, although the effects on OV90 were modest. None of the members of the cell line panel demonstrated identical patterns of responsiveness; for example, despite comparable baseline proliferation rates, OV90 and OVCAR4 exhibited only small $(<4 \%)$ changes in proliferation regardless of which growth factor was used while OVCA432 was strongly sensitive to several growth factors. Of the growth factors, the effects of NRG1 $\beta$ were the most widespread, with large increases in proliferation for Caov3, Caov4, OVCA432, and OVCAR3, a slight increase for OVCAR4, and a slight decrease for OV90. HB-EGF significantly induced proliferation for Caov3,
Caov4, and OVCA432, and a slight decrease in proliferation in OVCAR4 was seen. IGF1 induced proliferation in Caov3, OVCA432, and OVCAR3, with a slight increase for OV90. Finally, HGF increased proliferation for Caov3 and OVCAR3 with slight effects on Caov4 and OVCAR4.

\section{VEGF secretion in response to growth factors varied across HGSOC cell lines}

Production of VEGF by tumor cells and other cells in the microenvironment is essential for the development of new blood vessels to support tumor growth [32]; vessels that arise from VEGF-induced angiogenesis are often leaky, which in HGSOC results in the accumulation of large volumes of ascites fluid [14, 15]. Here, we analyzed the concentration of VEGF in conditioned media from six HGSOC cell lines after $24 \mathrm{~h}$ of stimulation with vehicle, HB-EGF, NRG1 $\beta$, IGF1, or HGF (Fig. 5). In the absence of 


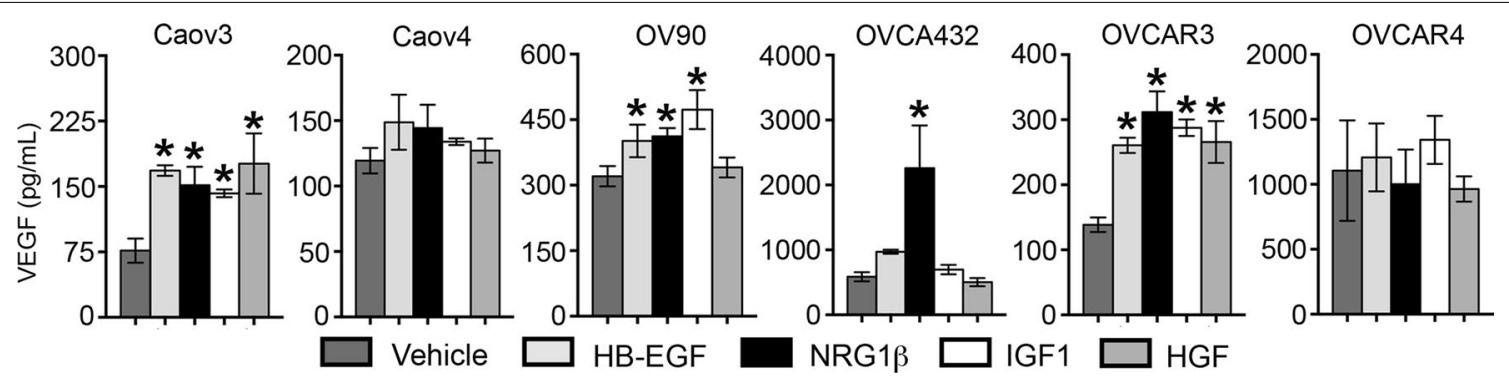

Fig. 5 The impact of growth factors on VEGF secretion by HGSOC cell lines. HGSOC cell lines secreted varying baseline levels of VEGF and treatment with $10 \mathrm{ng} / \mathrm{mL}$ HB-EGF, NRG1ß, IGF1, or HGF induced VEGF secretion in a subset of these cell lines. VEGF levels were determined by ELISA. Data presented as the average $\pm S D, n=3 .{ }^{*} p<0.05$ compared to vehicle. Note different scales on the $y$-axes

exogenous stimulation, all six cell lines secreted detectable levels of VEGF. These baseline concentrations varied greatly across the cell lines (ranging from $76.5 \mathrm{pg} / \mathrm{mL}$ for Caov3 to $1105.6 \mathrm{pg} / \mathrm{mL}$ for OVCAR4). Following growth factor treatment, VEGF levels increased in response to either: (1) all four growth factors (Caov3, OVCAR3), (2) a subset of growth factors (OV90, OVCA432), or (3) none of the tested growth factors (Caov4, OVCAR4). Overall, Caov3 and OVCAR3 showed the most similar response profile, with similar fold increases in response to each of the four tested growth factors. In contrast to the other behaviors studied, OV90 was responsive to growth factor stimulation, with increases in VEGF in response to HBEGF, NRG1 $\beta$, and IGF1. Among the growth factors, cells were most responsive to NRG1 $\beta$, with increased levels of VEGF seen in Caov3, OV90, OVCA432, and OVCAR3. HB-EGF treatment induced VEGF secretion in Caov3, OV90 and OVCAR3; despite impacting unique receptor tyrosine kinase families, cells showed a similar sensitivity to IGF1 as they had to HB-EGF. HGF increased VEGF levels only in Caov3 and OVCAR3.

\section{Principal component analysis suggested HGSOC cell response to growth factors is dependent on the cell line}

To examine patterns in our data, principal component analysis (PCA) was performed on the growth factorinduced effects on migration, $M M P 2$ expression, proliferation, and VEGF secretion. As seen in the scores plot (Fig. 6), cell lines clustered together more closely than growth factor treatments. Cell lines were primarily separated by principal component 1 ; for example, Caov4, OV90, and OVCAR4 were generally unresponsive to the selected growth factors and projected negatively along this axis, while Caov3 and OVCAR3 were generally sensitive and projected along the positive axis. In contrast, all four growth factors were distributed across both principal component 1 and principal component 2 .

We examined two potential reasons for this result. First, it is possible that the baseline behavior of the cells

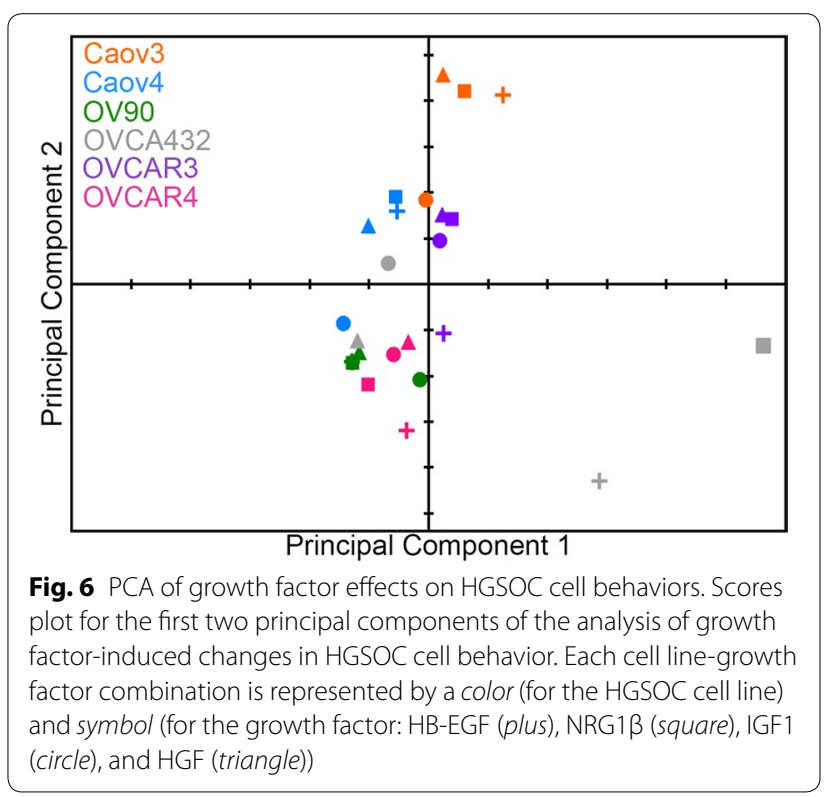

would influence the growth factor-induced response. For example, it is possible that cells with high basal production would not be able to produce additional VEGF. However, OVCA432 had the second highest basal level of VEGF $(587 \mathrm{pg} / \mathrm{mL}$ ), but was exquisitely sensitive to NRG1 $\beta$, and nearly quadrupled the amount of VEGF produced (2258 pg/mL, Fig. 5). Additionally, baseline migration levels of Caov3 and Caov4 were similar, but Caov3 was substantially more responsive to HB-EGF (Fig. 1). Secondly, the level of the receptors for the selected growth factor could influence the activity of the network upon growth factor treatment. In some cases, baseline receptor levels (Additional file 1) could predict sensitivity to growth factor treatment. For example, OV90 had the second lowest level of ErbB3, the receptor for NRG1 $\beta$, and was generally unresponsive to this growth factor (Figs. 1, 2, 3, 4). However, OV90 also had the highest levels of IGF1R and was insensitive to IGF1; indeed, in most 
cases there was no correlation between receptor level and growth factor response.

\section{Discussion}

In order to determine if HGSOC cell lines with genomic profiles similar to the TCGA database demonstrate heterogeneity similar to that seen clinically, we examined differences in baseline migration, MMP2 expression, proliferation and VEGF secretion, as well as responsiveness to HB-EGF, NRG1 $\beta$, IGF1 and HGF. As most prior studies have utilized only one or two cell lines, comparisons of the baseline behaviors for these cell lines have not been previously reported. Additionally, only twelve of the 120 growth factor-induced endpoints in this study have been examined before [20,25,33-38]. Similar to the heterogeneity observed between HGSOC tumors, our analysis indicated that there was substantial variation between these cell lines, and PCA of the data set indicated that the cell behaviors were more strongly influenced by cell type than growth factor identity.

Our results indicated that each of four tested growth factors impacted several behaviors across the cell line panel. Of the 24 different cell line-endpoint combinations, HB-EGF and NRG1 $\beta$ significantly increased 14 endpoints and HGF increased 12 endpoints (each of these growth factors also resulted in one behavior that was slightly decreased). While the results were generally consistent with previous reports for the members of the cell panel $[20,25,34,36,37]$ there were some noted differences relative to prior studies with SKOV3. For example, IGF1 did not stimulate migration in either of the assays, but has been shown to increase wound closure for SKOV3 [39]. Likewise, HGF had no effect on any cell line in the transwell assay but has been repeatedly shown to induce chemotactic migration in SKOV3 [38, 40, 41]. The diverse effects of the growth factors suggest that targeting one growth factor pathway will not be sufficient to abrogate tumor cell behavior and may help explain the inefficacy of receptor-targeted therapies in ovarian cancer [42-45]. One notable exception to this trend has been the promising results from clinical trials with anti-ErbB3 antibodies [46-48]. NRG1 $\beta$ stimulated proliferation and VEGF secretion in multiple cell lines suggesting this approach may successfully target multiple mechanisms in a larger population of patients.

Of the individual cellular behaviors examined, the selected growth factors had the strongest effect on proliferation, with three or more cell lines sensitive to each growth factor, and VEGF secretion, where each growth factor impacted at least two cell lines. This may of course result from the high sensitivity and precision of these assays and highlights the importance of considering assay choice when doing in vitro studies. The impact of assay choice was further exemplified by the striking differences observed between the wound and transwell assays for migration. While both assays are commonly used to measure cell migration, they examine different biological mechanisms as wound assays monitor collective cell migration and transwell assays assess single cell motility in response to chemotactic stimuli. Our results indicated that growth factors have a substantially stronger effect on collective migration versus single cell migration in the HGSOC cell lines. In addition, the effects of growth factor treatment on $M M P 2$ levels did not mirror the effects seen for migration, suggesting that unique therapeutic strategies may be required to control these different mechanisms of HGSOC metastasis.

It is of course important to compare our in vitro findings to data from clinical samples in order to determine if these cell lines that are representative of the HGSOC genotype [6] are also representative of its phenotype. The growth factors examined in this study have been previously suggested to have a role in HGSOC, are expressed in a high percentage of tumors, and are generally elevated compared to normal tissue [20, 49-53]. All growth factors were examined at a dose of $10 \mathrm{ng} / \mathrm{mL}$, reflecting the concentrations reported for HB-EGF and HGF in ascites fluid of ovarian cancer patients [52, 54]. All cell lines proliferated when treated with vehicle; however, the extent of proliferation varied depending on the cell line (16.8-34.8\%). This spread was consistent with variation observed in proliferation in primary tumors $(0.4-23.04 \%$ [55]), although the absolute levels were higher. Additionally, all cell lines secreted detectable levels of VEGF in culture $(76.5-1105.6 \mathrm{pg} / \mathrm{mL})$, which was consistent with reports of serum levels in HGSOC (92-721 pg/mL [56]). MMPs are often expressed in HGSOC $[57,58]$; thus, it was not surprising that all cell lines secreted detectable levels of MMPs. While it is not possible to directly relate these levels to reports from primary tumors, MMP levels varied between the examined lines and immunohistochemistry for MMP2 also showed variation between HGSOC samples [59].

Finally, even though a growth factor was capable of impacting a cell behavior in one cell line, there was no guarantee that it would impact another cell line, even if that other cell line was sensitive with respect to a different endpoint. For example, HB-EGF induced proliferation and migration in Caov3 but only proliferation for OVCA432. This is reflected in the clustering by cell type rather than growth factor in PCA. However, neither baseline cellular behaviors nor growth factor receptor levels were predictive of sensitivity. It is possible that variations in the levels of other components of the cellular signaling network besides growth factor receptors could be responsible for the observed heterogeneity. For example, 
it has been shown that when predicting cell response, dimerization patterns of ErbB1 with other ErbB receptors is important to consider [60], as is the ratio of IGF1 to IGF1R and the level of the IGF binding proteins [61]. Likewise, previous work from our lab demonstrated that it was necessary to incorporate the levels of both ligands and receptors when predicting ovarian cancer cell response to an ErbB-targeted inhibitor [62]. Ultimately, our analysis demonstrated that these six cell line models of HGSOC exhibit heterogeneity consistent with the disease. Our results also highlight the difficulty in developing targeted therapies for HGSOC since determining the target that will halt metastatic spread will not be as direct as simply identifying the growth factors or receptors present at the highest levels.

\section{Methods}

\section{Cell lines and culture methods}

Caov3 (HTB-75), Caov4 (HTB-76), OV90 (CRL-11732), OVCAR3 (HTB-161), and MDA-MB-231 were purchased from American Type Culture Collection (ATCC; Rockville, MD). OVCA432 [63] were obtained from Dr. R. Bast (MD Anderson Cancer Center; Houston, TX, USA). OVCAR4 [64] were obtained from the NCI Tumor Repository (Frederick, MD). HGSOC cell lines were authenticated by human short tandem repeat (STR) analysis at the Translational Research Initiatives in Pathology (TRIP) lab at the University of Wisconsin-Madison. Briefly, the analysis was conducted utilizing the Promega ${ }^{\circledR} 16$ HS reagent system, multiplex PCR amplification, capillary electrophoresis (ABI 3500) and GeneMapper (v.4.1) software. All HGSOC cell lines are reported to possess a mutation in TP53 (Table 1). Cells were maintained at $37^{\circ} \mathrm{C}$ in a humidified $5 \% \mathrm{CO}_{2}$ atmosphere. Caov3, Caov4, OV90, OVCA432, OVCAR4, and MDA-MB-231 were cultured in a 1:1 (v/v) ratio of MCDB 105 (Sigma-Aldrich; St. Louis, MO, USA) and Medium 199 (Corning; Corning, NY, USA) supplemented with $1 \%$ penicillin/streptomycin (Life Technologies; Grand Island, NY, USA) and $10 \%$ heat-inactivated fetal bovine serum (Life Technologies). OVCAR3 cells were cultured in

Table 1 TP53 mutation status of HGSOC cell lines utilized in this study

\begin{tabular}{ll}
\hline Cell line & TP53 mutation \\
\hline Caov3 & 406 C > T-Nonsense (Q136X) $[6,67,68]$ \\
Caov4 & $440 \mathrm{~T}>\mathrm{A}$-Missense (V147D) $[6,67,68]$ \\
OV90 & $643 \mathrm{~A}>\mathrm{C}$-Missense (S215R) $[6,67,69]$ \\
OVCA432 & $830 \mathrm{G}>\mathrm{T}$-Missense (C277F) $[67,70,71]$ \\
OVCAR3 & $743 \mathrm{G}>\mathrm{A}$-Missense (R248Q) $[6,70-73]$ \\
OVCAR4 & $388 \mathrm{C}>\mathrm{G}$-Missense (L130 V) $[6]$ \\
\hline
\end{tabular}

RPMI 1640 (Corning) supplemented with $20 \%$ heat-inactivated fetal bovine serum, $1 \%$ penicillin/streptomycin, $1 \%$ sodium pyruvate (Sigma), $0.3 \%$ glucose (Corning), and $10 \mathrm{ng} / \mathrm{mL}$ insulin (Sigma).

\section{Tumor cell migration}

For wound assays, HGSOC cells were stained with $5 \mu \mathrm{M}$ CellTracker ${ }^{\text {TM }}$ Green CMFDA Dye (Life Technologies), plated in 48-well plates at cell densities empirically determined to result in $100 \%$ confluency, and allowed to attach overnight. Specifically, Caov3, Caov4, and OV90 were plated at 132,000 cells $/ \mathrm{cm}^{2}$, OVCA432 and OVCAR3 at 105,000 cells/ $/ \mathrm{cm}^{2}$, and OVCAR4 at 121,000 cells $/ \mathrm{cm}^{2}$. Cells were then rinsed with PBS and serumfree media was added. After serum starving for $24 \mathrm{~h}$, a scratch was made in each well with a $200 \mu \mathrm{L}$ pipette tip, cells were washed twice with serum-free media, and the wound was imaged with an Olympus IX51 Fluorescent Microscope (Olympus America Inc.; Center Valley, PA, USA). Cells were then treated with vehicle (0.1\% BSA in PBS) or $10 \mathrm{ng} / \mathrm{mL}$ recombinant human HB-EGF, NRG1 $\beta$, IGF1, or HGF (Peprotech; Rocky Hill, NJ, USA) in serumfree media. Forty-eight hours post-treatment, the wound was imaged again, and the percent wound closure was measured using ImageJ (NIH; Bethesda, MD, USA).

Transwell assays were performed using polycarbonate Transwell ${ }^{\circledR}$ inserts (\#3422, Corning) with $8 \mu \mathrm{m}$ pores. HGSOC cells were serum starved for $24 \mathrm{~h}$, dissociated using TrypLE Select Enzyme (Life Technologies), and 150,000 cells/well were seeded in serum free media in the top compartments of the transwells inserted in 24-well plates. The bottom compartments contained 500 $\mu \mathrm{L}$ serum free media plus vehicle $(0.1 \% \mathrm{BSA}$ in PBS) or $10 \mathrm{ng} / \mathrm{mL}$ HB-EGF, NRG1 $\beta$, IGF1, or HGF. All experiments included a positive control of the highly invasive MDA-MB-231 breast cancer cell line [65] in the top compartment and $10 \%$ serum-containing media in the bottom compartment. After $48 \mathrm{~h}$ of treatment, any cells which had migrated through the transwell into the bottom compartment were dissociated and stained for 30 min at $37^{\circ} \mathrm{C}$ with $400 \mu \mathrm{L}$ of a $4 \mu \mathrm{M}$ Calcein AM (Life Technologies)/TrypLE dissociation solution. After dissociation and staining, $100 \mu \mathrm{L}$ of each well was transferred to a black-walled, 96-well plate (Corning) and analyzed at $485 \mathrm{~nm}$ excitation and $520 \mathrm{~nm}$ emission using a Fluoroskan Ascent ${ }^{\mathrm{TM}}$ Microplate Fluorometer (Thermo Scientific; Waltham, MA, USA).

\section{MMP characterization}

To characterize total levels of active MMPs, HGSOC cells were plated in 12-well plates at cell densities empirically determined to result in approximately $70 \%$ confluency and allowed to attach overnight. Specifically, 
Caov3, Caov4, and OV90 were plated at 29,000 cells/ $\mathrm{cm}^{2}$, OVCA432 and OVCAR3 at 24,000 cells/ $\mathrm{cm}^{2}$, and OVCAR4 at 26,000 cells $/ \mathrm{cm}^{2}$. Cells were then rinsed with PBS and serum-free media was added. After $48 \mathrm{~h}$ of serum starvation, conditioned media was collected and assayed at a 1:1 (v/v) ratio with $20 \mu \mathrm{M}$ Mca-PLGL-DpaAR-NH2 fluorogenic MMP substrate (R\&D Systems: Minneapolis, MN) in 96-well, black-walled plates. After a $24 \mathrm{~h}$ incubation at $37^{\circ} \mathrm{C}$, MMP activity was measured by quantifying fluorescent intensity at an excitation/emission of 320/405 nm. To determine the impact of growth factors on $M M P 2$ expression, cells were plated in 6-well plates at the same cell densities as the total MMP assay. After overnight attachment, cells were washed with PBS and serum-free media was added. Following $24 \mathrm{~h}$ of serum starvation, cells were washed with $\mathrm{PBS}$ and vehicle $(0.1 \%$ BSA in PBS) or $10 \mathrm{ng} / \mathrm{mL}$ HB-EGF, NRG1 $\beta$, IGF1, or HGF was added in serum-free media. After $24 \mathrm{~h}$ of growth factor treatment, mRNA was isolated using the RNeasy Mini Kit (Qiagen; Hilden, Germany) according to manufacturer's instructions and quantified on a NanoDrop 2000 Spectrophotometer (Thermo Scientific Pierce). cDNA was synthesized from $1 \mu \mathrm{g}$ RNA using the Superscript III First-Strand Synthesis System kit (Life Technologies) according to manufacturer's instructions. qRT-PCR was performed on $100 \mathrm{ng}$ cDNA using SYBR Green PCR Master Mix (Life Technologies) and QuantiTect primers for MMP2 (QT00088396, Qiagen) or GAPDH (QT00079247, Qiagen). The fold change in gene expression of $M M P 2$ was determined by the $\triangle \triangle \mathrm{C}_{\mathrm{t}}$ method relative to GAPDH expression.

\section{Tumor cell proliferation}

HGSOC cells were plated in 12-well plates at the same cell densities as the MMP2 expression assay and allowed to attach overnight. Cells were then rinsed with PBS and serum-free media was added. After serum starving for $24 \mathrm{~h}$, cells were washed with PBS and stimulated with vehicle (0.1\% BSA in PBS) or $10 \mathrm{ng} / \mathrm{mL} \mathrm{HB}-\mathrm{EGF}$, NRG1 $\beta$, IGF1, or HGF in serum-free media. After $24 \mathrm{~h}$ of treatment, cell proliferation was quantified using the Click-iT ${ }^{\circledR}$ EdU Alexa Fluor ${ }^{\circledR} 488$ flow cytometry assay (Life Technologies) according to manufacturer's instructions. Cells were incubated with EdU for $6 \mathrm{~h}$ prior to sample collection and analyzed on a BD Accuri ${ }^{\text {TM }}$ C6 flow cytometer (BD; Franklin Lakes, NJ, USA). Samples were gated for the EdU-positive population to determine the percentage of cells that entered S-phase during the EdU incubation.

\section{VEGF secretion}

HGSOC cells were plated in 12-well plates at the same cell densities as the MMP2 expression assay and allowed to attach overnight. Cells were then rinsed with PBS and serum-free media was added. After serum starving for $24 \mathrm{~h}$, cells were washed with PBS and vehicle $(0.1 \%$ BSA in PBS) or $10 \mathrm{ng} / \mathrm{mL}$ HB-EGF, NRG1 $\beta$, IGF1, or HGF was added in serum-free media. After $24 \mathrm{~h}$ of growth factor treatment, conditioned media was collected, and VEGF levels were determined by ELISA (\#DY293B, R\&D Systems) according to the manufacturer's instructions.

\section{Principal component analysis}

Principal component analysis (PCA, [66]) was performed on the resulting data matrix (composed of rows for each cell line-growth factor combination and columns of the levels of growth factor-induced response relative to vehicle-treated controls-i.e., percent increase in proliferation, percent increase in wound closure, fold change in fluorescence for transwell migration, fold change in $M M P 2$, fold change in VEGF). The first principal component captured $47.0 \%$ of the variation; inclusion of a second principal component increased this to $74.7 \%$. PCA was performed using SIMCA.P + v.12.0.1 (Umetrics; San Jose, CA, USA) with mean-centered and variance-scaled data.

\section{Statistical analysis}

All data are presented as the mean \pm standard deviation $(\mathrm{n}=3)$. Additionally, all experiments were performed at least twice to ensure reproducibility. Statistical significance was determined using Dunnett's with vehicle samples set as the control. All statistical calculations were performed with JMP 4.1 software (SAS Institute; Cary, NC, USA), with statistical significance set as $\mathrm{p}<0.05$.

\section{Additional file}

Additional file 1. Baseline receptor levels in $\mathrm{HGSOC}$ cell lines. Baseline levels of ErbB1, ErbB3, IGF1R, and MET receptors varied across the subset of six HGSOC cell lines. Shown are (A) representative blots and (B) quantification by densitometry relative to a concurrently-run control lysate. Data presented as the average $\pm S D, n=3$.

\section{Abbreviations}

HGSOC: high-grade serous ovarian cancer; MMP2: matrix-metalloproteinase-2; VEGF: vascular endothelial growth factor; HB-EGF: heparin-binding EGF-like growth factor; NRG1 $\beta$ : neuregulin-1-beta; IGF1: insulin-like growth factor 1 ; HGF: hepatocyte growth factor; PCA: principal component analysis.

\section{Authors' contributions}

DB participated in the design of the study, performed the experimental analysis, developed and analyzed the PCA model, and drafted the manuscript. KK and VP helped perform experimental analysis. PKK conceived of the study, participated in its design, and drafted the manuscript. All authors read and approved the final manuscript.

\section{Acknowledgements}

We wish to acknowledge Sarah Dicker for her help with protein assays and proliferation experiments, as well as Molly Carroll, Anthony Desotell, and Andy Fleszar for helpful discussions and critical reading of the manuscript. Cell line 
authentication was performed through the University of Wisconsin Carbone Cancer Center (P30 CA014520). This work was supported by an American Cancer Society Research Scholars Grant (RSG-13-026-01-CSM, PKK) and a National Institutes of Health New Innovator Award (1DP2CA195766-01, PKK).

\section{Competing interests}

The authors declare that they have no competing interests.

Received: 10 July 2015 Accepted: 26 November 2015

Published online: 07 December 2015

\section{References}

1. Siegel R, Ma J, Zou Z, Jemal A. Cancer statistics, 2014. CA Cancer J Clin. 2014;64(1):9-29.

2. Kobel M, Kalloger SE, Boyd N, McKinney S, Mehl E, Palmer C, Leung S, Bowen NJ, lonescu DN, Rajput A, et al. Ovarian carcinoma subtypes are different diseases: implications for biomarker studies. PLoS Med. 2008;5(12):e232

3. Soslow RA. Histologic subtypes of ovarian carcinoma: an overview. Int J Gynecol Pathol. 2008;27(2):161-74.

4. Perets R, Wyant GA, Muto KW, Bijron JG, Poole BB, Chin KT, Chen JY, Ohman AW, Stepule CD, Kwak S, et al. Transformation of the fallopian tube secretory epithelium leads to high-grade serous ovarian cancer in Brca;Tp53;Pten models. Cancer Cell. 2013;24(6):751-65.

5. Sherman-Baust CA, Kuhn E, Valle BL, Shih le M, Kurman RJ, Wang TL, Amano T, Ko MS, Miyoshi I, Araki Y, et al. A genetically engineered ovarian cancer mouse model based on fallopian tube transformation mimics human highgrade serous carcinoma development. J Pathol. 2014;233(3):228-37.

6. Domcke S, Sinha R, Levine DA, Sander C, Schultz N. Evaluating cell lines as tumour models by comparison of genomic profiles. Nat Commun. 2013:4:2126.

7. Lengyel E. Ovarian cancer development and metastasis. Am J Pathol. 2010;177(3):1053-64.

8. Saga Y, Mizukami H, Suzuki M, Urabe M, Kume A, Nakamura T, Sato I, Ozawa K. Expression of HGF/NK4 in ovarian cancer cells suppresses intraperitoneal dissemination and extends host survival. Gene Ther. 2001;8(19):1450-5.

9. Kenny HA, Kaur S, Coussens LM, Lengyel E. The initial steps of ovarian cancer cell metastasis are mediated by MMP-2 cleavage of vitronectin and fibronectin. J Clin Investig. 2008;118(4):1367-79.

10. Planaguma J, Liljestrom M, Alameda F, Butzow R, Virtanen I, Reventos J, Hukkanen M. Matrix metalloproteinase-2 and matrix metalloproteinase-9 codistribute with transcription factors RUNX1/AML1 and ETV5/ERM at the invasive front of endometrial and ovarian carcinoma. Hum Pathol. 2011;42(1):57-67.

11. Graves LE, Ariztia EV, Navari JR, Matzel HJ, Stack MS, Fishman DA. Proinvasive properties of ovarian cancer ascites-derived membrane vesicles. Cancer Res. 2004;64(19):7045-9.

12. Perigny M, Bairati I, Harvey I, Beauchemin M, Harel F, Plante M, Tetu B. Role of immunohistochemical overexpression of matrix metalloproteinases MMP-2 and MMP-11 in the prognosis of death by ovarian cancer. Am J Clin Pathol. 2008;129(2):226-31.

13. Anttila MA, Kosma VM, Hongxiu J, Puolakka J, Juhola M, Saarikoski S, Syrjanen K. p21/WAF1 expression as related to p53, cell proliferation and prognosis in epithelial ovarian cancer. Br J Cancer. 1999;79(11-12):1870-8.

14. Xu L, Yoneda J, Herrera C, Wood J, Killion JJ, Fidler IJ. Inhibition of malignant ascites and growth of human ovarian carcinoma by oral administration of a potent inhibitor of the vascular endothelial growth factor receptor tyrosine kinases. Int J Oncol. 2000;16(3):445-54.

15. Kassim SK, El-Salahy EM, Fayed ST, Helal SA, Helal T, Azzam Eel D, Khalifa A. Vascular endothelial growth factor and interleukin-8 are associated with poor prognosis in epithelial ovarian cancer patients. Clin Biochem. 2004;37(5):363-9.

16. Byrne AT, Ross L, Holash J, Nakanishi M, Hu L, Hofmann Jl, Yancopoulos GD, Jaffe RB. Vascular endothelial growth factor-trap decreases tumor burden, inhibits ascites, and causes dramatic vascular remodeling in an ovarian cancer model. Clin Cancer Res Off J Am Assoc Cancer Res. 2003;9(15):5721-8.
17. Hikita S, Yotsumoto F, Fukami T, Horiuchi S, Sanui A, Miyata K, Nam SO, Tsujioka H, Ueda T, Shirota K, et al. Assessment of HB-EGF levels in peritoneal fluid and serum of ovarian cancer patients using ELISA. Anticancer Res. 2011;31(7):2553-9.

18. Tsujioka H, Yotsumoto F, Hikita S, Ueda T, Kuroki M, Miyamoto S. Targeting the heparin-binding epidermal growth factor-like growth factor in ovarian cancer therapy. Curr Opin Obstet Gynecol. 2011;23(1):24-30.

19. Yagi H, Miyamoto S, Tanaka Y, Sonoda K, Kobayashi H, Kishikawa T, Iwamoto R, Mekada E, Nakano H. Clinical significance of heparin-binding epidermal growth factor-like growth factor in peritoneal fluid of ovarian cancer. Br J Cancer. 2005;92(9):1737-45.

20. Gilmour LM, Macleod KG, MCCaig A, Sewell JM, Gullick WJ, Smyth JF, Langdon SP. Neuregulin expression, function, and signaling in human ovarian cancer cells. Clin Cancer Res Off J Am Assoc Cancer Res. 2002;8(12):3933-42.

21. Sheng Q, Liu X, Fleming E, Yuan K, Piao H, Chen J, Moustafa Z, Thomas RK, Greulich H, Schinzel A, et al. An activated ErbB3/NRG1 autocrine loop supports in vivo proliferation in ovarian cancer cells. Cancer Cell. 2010;17(3):298-310.

22. Tanaka Y, Miyamoto S, Suzuki SO, Oki E, Yagi H, Sonoda K, Yamazaki A, Mizushima H, Maehara Y, Mekada E, et al. Clinical significance of heparinbinding epidermal growth factor-like growth factor and a disintegrin and metalloprotease 17 expression in human ovarian cancer. Clin Cancer Res Off J Am Assoc Cancer Res. 2005;11(13):4783-92.

23. Yagi $H$, Yotsumoto F, Miyamoto S. Heparin-binding epidermal growth factor-like growth factor promotes transcoelomic metastasis in ovarian cancer through epithelial-mesenchymal transition. Mol Cancer Ther. 2008;7(10):3441-51

24. Brokaw J, Katsaros D, Wiley A, Lu L, Su D, Sochirca O, de la Longrais IA, Mayne S, Risch H, Yu H. IGF-I in epithelial ovarian cancer and its role in disease progression. Growth Factors. 2007;25(5):346-54.

25. Shen MR, Lin AC, Hsu YM, Chang TJ, Tang MJ, Alper SL, Ellory JC, Chou CY. Insulin-like growth factor 1 stimulates $\mathrm{KCl}$ cotransport, which is necessary for invasion and proliferation of cervical cancer and ovarian cancer cells. J Biol Chem. 2004;279(38):40017-25.

26. Aune G, Lian AM, Tingulstad S, Torp SH, Forsmo S, Reseland JE, Stunes AK, Syversen U. Increased circulating hepatocyte growth factor (HGF): a marker of epithelial ovarian cancer and an indicator of poor prognosis. Gynecol Oncol. 2011;121(2):402-6.

27. Pon YL, Zhou HY, Cheung AN, Ngan HY, Wong AS. p70 S6 kinase promotes epithelial to mesenchymal transition through snail induction in ovarian cancer cells. Cancer Res. 2008;68(16):6524-32.

28. Tang MK, Zhou HY, Yam JW, Wong AS. c-Met overexpression contributes to the acquired apoptotic resistance of nonadherent ovarian cancer cells through a cross talk mediated by phosphatidylinositol 3-kinase and extracellular signal-regulated kinase 1/2. Neoplasia. 2010;12(2):128-38.

29. Hudson LG, Zeineldin R, Stack MS. Phenotypic plasticity of neoplastic ovarian epithelium: unique cadherin profiles in tumor progression. Clin Exp Metastasis. 2008;25(6):643-55.

30. Kramer N, Walzl A, Unger C, Rosner M, Krupitza G, Hengstschlager $\mathrm{M}$, Dolznig $\mathrm{H}$. In vitro cell migration and invasion assays. Mutat Res. 2013;752(1):10-24.

31. Kessenbrock K, Wang CY, Werb Z: Matrix metalloproteinases in stem cell regulation and cancer. Matrix Biol J Int Soc Matrix Biol 2015:44-46C:184-190.

32. Matsumoto K, Ema M. Roles of VEGF-A signalling in development, regeneration, and tumours. J Biochem. 2014;156(1):1-10.

33. Bolitho C, Hahn MA, Baxter RC, Marsh DJ. The chemokine CXCL1 induces proliferation in epithelial ovarian cancer cells by transactivation of the epidermal growth factor receptor. Endocr Relat Cancer. 2010;17(4):929-40.

34. Cao Z, Fang J, Xia C, Shi X, Jiang BH. trans-3,4,5'-Trihydroxystibene inhibits hypoxia-inducible factor 1 alpha and vascular endothelial growth factor expression in human ovarian cancer cells. Clin Cancer Res Off J Am Assoc Cancer Res. 2004;10(15):5253-63.

35. Kwon Y, Smith BD, Zhou Y, Kaufman MD, Godwin AK. Effective inhibition of c-MET-mediated signaling, growth and migration of ovarian cancer cells is influenced by the ovarian tissue microenvironment. Oncogene. 2015:34(2):144-53.

36. Moran-Jones K, Brown LM, Samimi G. INC280, an orally available small molecule inhibitor of c-MET, reduces migration and adhesion in ovarian cancer cell models. Scientific Reports. 2015;5:11749. 
37. Xu F, Yu Y, Le XF, Boyer C, Mills GB, Bast RC Jr. The outcome of heregulininduced activation of ovarian cancer cells depends on the relative levels of HER-2 and HER-3 expression. Clin Cancer Res Off J Am Assoc Cancer Res. 1999;5(11):3653-60.

38. Zhou HY, Wong AS. Activation of p70S6 K induces expression of matrix metalloproteinase 9 associated with hepatocyte growth factormediated invasion in human ovarian cancer cells. Endocrinology. 2006;147(5):2557-66.

39. Whitley BR, Beaulieu LM, Carter JC, Church FC. Phosphatidylinositol 3-kinase/Akt regulates the balance between plasminogen activator inhibitor-1 and urokinase to promote migration of SKOV-3 ovarian cancer cells. Gynecol Oncol. 2007;104(2):470-9.

40. Corps AN, Sowter HM, Smith SK. Hepatocyte growth factor stimulates motility, chemotaxis and mitogenesis in ovarian carcinoma cells expressing high levels of c-met. Int J Cancer J Int du Cancer. 1997;73(1):151-5

41. Ueoka Y, Kato K, Kuriaki Y, Horiuchi S, Terao Y, Nishida J, Ueno H, Wake N. Hepatocyte growth factor modulates motility and invasiveness of ovarian carcinomas via Ras-mediated pathway. Br J Cancer. 2000;82(4):891-9.

42. Schilder RJ, Sill MW, Chen X, Darcy KM, Decesare SL, Lewandowski G, Lee RB, Arciero CA, Wu H, Godwin AK. Phase II study of gefitinib in patients with relapsed or persistent ovarian or primary peritoneal carcinoma and evaluation of epidermal growth factor receptor mutations and immunohistochemical expression: a Gynecologic Oncology Group Study. Clin Cancer Res Off J Am Assoc Cancer Res. 2005;11(15):5539-48.

43. Seiden MV, Burris HA, Matulonis U, Hall JB, Armstrong DK, Speyer J, Weber JD, Muggia F. A phase II trial of EMD72000 (matuzumab), a humanized anti-EGFR monoclonal antibody, in patients with platinumresistant ovarian and primary peritoneal malignancies. Gynecol Oncol. 2007;104(3):727-31.

44. Gordon AN, Finkler N, Edwards RP, Garcia AA, Crozier M, Irwin DH, Barrett $\mathrm{E}$. Efficacy and safety of erlotinib $\mathrm{HCl}$, an epidermal growth factor receptor (HER1/EGFR) tyrosine kinase inhibitor, in patients with advanced ovarian carcinoma: results from a phase II multicenter study. Int J Gynecol Cancer Off J Int Gynecol Cancer Soc. 2005;15(5):785-92.

45. Gordon MS, Sweeney CS, Mendelson DS, Eckhardt SG, Anderson A, Beaupre DM, Branstetter D, Burgess TL, Coxon A, Deng H, et al. Safety, pharmacokinetics, and pharmacodynamics of AMG 102, a fully human hepatocyte growth factor-neutralizing monoclonal antibody, in a first-inhuman study of patients with advanced solid tumors. Clin Cancer Res Off J Am Assoc Cancer Res. 2010;16(2):699-710.

46. Schoeberl B, Pace EA, Fitzgerald JB, Harms BD, Xu L, Nie L, Linggi B, Kalra $A$, Paragas $V$, Bukhalid R et al: Therapeutically targeting ErbB3: a key node in ligand-induced activation of the ErbB receptor-PI3K axis. Sci Signal 2009;2(77):ra31.

47. Jiang N, Wang D, Hu Z, Shin HJ, Qian G, Rahman MA, Zhang H, Amin AR, Nannapaneni S, Wang X, et al. Combination of anti-HER3 antibody MM-121/SAR256212 and cetuximab inhibits tumor growth in preclinical models of head and neck squamous cell carcinoma. Mol Cancer Ther. 2014;13(7):1826-36

48. Huang J, Wang S, Lyu H, Cai B, Yang X, Wang J, Liu B. The anti-erbB3 antibody MM-121/SAR256212 in combination with trastuzumab exerts potent antitumor activity against trastuzumab-resistant breast cancer cells. Mol Cancer. 2013;12(1):134.

49. Baykal C, Demirtas E, Al A, Ayhan A, Yuce K, Tulunay G, Kose MF, Ayhan A. Comparison of HGF (hepatocyte growth factor) levels of epithelial ovarian cancer cyst fluids with benign ovarian cysts. Int J Gynecol Cancer Off J Int Gynecol Cancer Soc. 2003;13(6):771-5.

50. Goode EL, Chenevix-Trench G, Hartmann LC, Fridley BL, Kalli KR, Vierkant RA, Larson MC, White KL, Keeney GL, Oberg TN, et al. Assessment of hepatocyte growth factor in ovarian cancer mortality. Cancer Epidemiol Biomarkers Prevent Publ Am Assoc Cancer Res Cosponsored by the Am Soc Prevent Oncol. 2011;20(8):1638-48.

51. Lukanova A, Lundin E, Toniolo P, Micheli A, Akhmedkhanov A, Rinaldi S, Muti P, Lenner P, Biessy C, Krogh V, et al. Circulating levels of insulin-like growth factor-I and risk of ovarian cancer. Int J Cancer. 2002;101(6):549-54

52. Miyamoto S, Hirata M, Yamazaki A, Kageyama T, Hasuwa H, Mizushima H, Tanaka Y, Yagi H, Sonoda K, Kai M, et al. Heparin-binding EGF-like growth factor is a promising target for ovarian cancer therapy. Cancer Res. 2004:64(16):5720-7.
53. Tworoger SS, Lee IM, Buring JE, Pollak MN, Hankinson SE. Insulin-like growth factors and ovarian cancer risk: a nested case-control study in three cohorts. Cancer Epidemiol Biomarkers Prevent. 2007;16(8):1691-5.

54. Sowter HM, Corps AN, Smith SK. Hepatocyte growth factor (HGF) in ovarian epithelial tumour fluids stimulates the migration of ovarian carcinoma cells. Int J Cancer. 1999;83(4):476-80.

55. Salihoglu Y, Bilir A, Aydiner A, Erkan M, Tuzlali S, Eralp Y. Thymidine labeling index in epithelial ovarian cancer. Int J Gynaecol Obstetr Off Organ Int Feder Gynaecol Obstetr. 2001;75(2):171-6.

56. Yamamoto S, Konishi I, Mandai M, Kuroda H, Komatsu T, Nanbu K, Sakahara H, Mori T. Expression of vascular endothelial growth factor (VEGF) in epithelial ovarian neoplasms: correlation with clinicopathology and patient survival, and analysis of serum VEGF levels. Br J Cancer. 1997;76(9):1221-7.

57. Brun JL, Cortez A, Commo F, Uzan S, Rouzier R, Darai E. Serous and mucinous ovarian tumors express different profiles of MMP-2, -7, -9, MT1-MMP, and TIMP-1 and -2. Int J Oncol. 2008;33(6):1239-46.

58. Kamat AA, Fletcher M, Gruman LM, Mueller P, Lopez A, Landen CN Jr, Han L, Gershenson DM, Sood AK. The clinical relevance of stromal matrix metalloproteinase expression in ovarian cancer. Clin Cancer Res Off J Am Assoc Cancer Res. 2006;12(6):1707-14.

59. Adley BP, Gleason KJ, Yang XJ, Stack MS. Expression of membrane type 1 matrix metalloproteinase (MMP-14) in epithelial ovarian cancer: high level expression in clear cell carcinoma. Gynecol Oncol. 2009;112(2):319-24.

60. Amann J, Kalyankrishna S, Massion PP, Ohm JE, Girard L, Shigematsu H, Peyton M, Juroske D, Huang Y, Stuart Salmon J, et al. Aberrant epidermal growth factor receptor signaling and enhanced sensitivity to EGFR inhibitors in lung cancer. Cancer Res. 2005;65(1):226-35.

61. Tian D, Kreeger PK. Analysis of the quantitative balance between insulinlike growth factor (IGF)-1 ligand, receptor, and binding protein levels to predict cell sensitivity and therapeutic efficacy. BMC Syst Biol. 2014;8:98

62. Prasasya RD, Vang KZ, Kreeger PK. A multivariate model of ErbB network composition predicts ovarian cancer cell response to canertinib. Biotechnol Bioeng. 2012;109(1):213-24.

63. Bast RC Jr, Feeney M, Lazarus H, Nadler LM, Colvin RB, Knapp RC. Reactivity of a monoclonal antibody with human ovarian carcinoma. J Clin Investig. 1981;68(5):1331-7.

64. Hamilton TC, Young RC, Ozols RF. Experimental model systems of ovarian cancer: applications to the design and evaluation of new treatment approaches. Semin Oncol. 1984;11(3):285-98.

65. Gordon LA, Mulligan KT, Maxwell-Jones H, Adams M, Walker RA, Jones JL. Breast cell invasive potential relates to the myoepithelial phenotype. Int J Cancer. 2003;106(1):8-16.

66. Janes KA, Yaffe MB. Data-driven modelling of signal-transduction networks. Nat Rev Mol Cell Biol. 2006;7(11):820-8.

67. Langland GT, Yannone SM, Langland RA, Nakao A, Guan Y, Long SB, Vonguyen L, Chen DJ, Gray JW, Chen F. Radiosensitivity profiles from a panel of ovarian cancer cell lines exhibiting genetic alterations in p53 and disparate DNA-dependent protein kinase activities. Oncol Rep. 2010;23(4):1021-6.

68. Yaginuma $Y$, Westphal $H$. Abnormal structure and expression of the p53 gene in human ovarian carcinoma cell lines. Cancer Res. 1992;52(15):4196-9.

69. Samouelian V, Maugard CM, Jolicoeur M, Bertrand R, Arcand SL, Tonin PN, Provencher DM, Mes-Masson AM. Chemosensitivity and radiosensitivity profiles of four new human epithelial ovarian cancer cell lines exhibiting genetic alterations in BRCA2, TGFbeta-RII, KRAS2, TP53 and/or CDNK2A. Cancer Chemother Pharmacol. 2004;54(6):497-504.

70. Havrilesky LJ, Alvarez AA, Whitaker RS, Marks JR, Berchuck A. Loss of expression of the p16 tumor suppressor gene is more frequent in advanced ovarian cancers lacking p53 mutations. Gynecol Oncol. 2001;83(3):491-500

71. Wolf JK, Mills GB, Bazzet L, Bast RC Jr, Roth JA, Gershenson DM. Adenovirus-mediated p53 growth inhibition of ovarian cancer cells is independent of endogenous p53 status. Gynecol Oncol. 1999;75(2):261-6.

72. Debernardis D, Sire EG, De Feudis P, Vikhanskaya F, Valenti M, Russo P, Parodi S, D'Incalci M, Broggini M. p53 status does not affect sensitivity of human ovarian cancer cell lines to paclitaxel. Cancer Res. 1997:57(5):870-4

73. Gibb RK, Taylor DD, Wan T, O'Connor DM, Doering DL, Gercel-Taylor C. Apoptosis as a measure of chemosensitivity to cisplatin and taxol therapy in ovarian cancer cell lines. Gynecol Oncol. 1997;65(1):13-22. 